\title{
As faces da violência: aproximações, pesquisas e reflexões
}

\author{
Gisele Aparecida da Silva Alves - Universidade São Francisco ${ }^{1}$
}

Romaro, R. A. (2007). As faces da violência: aproximações, pesquisas e reflexões. São Paulo: Vetor. 264 p.

Observa-se no senso comum e na comunidade científica o crescente interesse por temáticas sobre a violência e relacionadas a ela, visto que o fenômeno afeta a sociedade de um modo geral, ao longo de sua história. Tal interesse tem fomentado discussões, reflexões e debates, sendo a violência estudada sob diversas percpectivas.

Com o objetivo de debater sobre violência na interface com sua pluralidade temática, o livro As faces da violência: aproximações, pequisas e reflexões, organizado por Rita Aparecida Romaro e Cláudio Capitão Garcia, é produto de profissionais e pesquisadores que trazem contribuições que visam ampliar reflexões e atuações nas mais diversas áreas. O livro é composto por 11 capítulos. No primeiro, As faces da violência: da conceituação polissêmica à sua emergência no campo da saúde, o autor Drausio Vicente Camarnado Junior faz uma reflexão acerca de aspectos históricos e sociopolitico-econômicos da violência, relacionando-a com ética na conceituação da saúde, de forma a considerar sua epistemologia. Nesse sentido, ressalta a relação necessária da saúde com a falta de violência.

Nos dois capítulos seguintes, a temática é duscutida ao considerar a interface de tal tema com a família. No segundo capítulo, Interfaces da violência no trabalho e na familia, Lis Andréa Pereira Soboll e José Roberto Heloani, além de discutirem as relações de violência na família, consideram também tais relações no trabalho ao apresentarem um estudo de caso de uma trabalhadora, contento assuntos relativos a assédio moral no trabalho e como isso repercutiu nas relações familiares. Já no terceiro capítulo, Suporte familiar $e$ violência, Makilim Nunes Baptista aborda a importância da percepção do suporte familiar no desenvolvimento psicossocial de crianças e adolescentes, discutindo as influências que essa percepção pode ter sobre o desenvolvimento dessa população, podendo servir como um fator protetivo ou de risco à violência.

Elizelma Ortêncio Ferreira e Cláudio Capitão Garcia abordam, no quarto capítulo, intitulado Tolerância à frustração e agressão: comportamento delinqüente, assuntos relativos à forma, como comportamentos considerados anti-sociais podem ser influenciados por fatores sociais, além dos intrínsecos e de personalidade.
No capítulo 5, A violência doméstica notificada no Conselho Tutelar, os autores Cláudio Garcia Capitão e Rita Aparecida Romaro fazem apresentação de uma pesquisa documental em 305 prontuários contendo casos de denúncias de violência doméstica feitos em conselhos tutelares do estado de São Paulo, trazendo análises com dados sociodemográficos dos casos, das vítimas, dos agressores e formas de registro e encaminhamento dos conselhos tutelares.

Nos próximos três capítulos, a temática é duscutida ao abordar o abuso sexual como forma de violência. No Capítulo 6, Carcaterização do abuso sexual em crianças e adolescentes, Cláudio Garcia Capitão e Rita Aparecida Romaro se referem a uma pesquisa realizada com uma amostra de 463 universitários, que objetivou caracterizar as principais formas de abuso sexual, como foi praticado e por quem, da forma como ele é lembrado posteriormente. As discussões realizadas na pesquisa abordam a forma como tais abusos podem influenciar, de alguma maneira, a vida adulta das vítimas, considerando suas conseqüências psicológicas. Cláudio Garcia Capitão, Flávia Nunes de Moraes Beraldo e Katya Luciane de Oliveira, no capítulo 7, Violência e abuso sexual; um breve estudo retrospectivo com universitários, caracterizam o comportamento sexual de jovens universitários que sofreram abuso sexual quando crianças e, ao analisarem os dados, questionam a atuação governamental.

Em Abuso sexual na infância e validade de instrumentos projetivos, capítulo 8, os autores Ana Rita Fonseca e Cláudio Garcia Capitão apresentam estudos de validade de instumento projetivos para a avaliação do abuso sexual. No capítulo 9, O campo da relação médico-paciente: quando a violência é revelada na prática médica, Cássia Maria de Paula e Cláudio Garcia Capitão apresentam formas como a relação médico-paciente pode expressar violência na prática médica. Os autores fazem uma discussão pertinente sobre a formação desses profissionais, para que relações de violência na relação médico-paciente possam ser mais bem enfrentadas. No capítulo 10, A violênia nos programas e serviços de saúde em DST/AIDS: com a palavra os usuários e os profissionais de saúde, os autores Darusio Vicente Camarnado Junior e Wilza Vieira Villela trazem uma discussão a respeito da violência apresentada na relação entre usuários e profissionais de programas de saúde em DST/AIDS no

\footnotetext{
${ }^{1}$ Endereço para correspondência:

Universidade São Francisco - Programa de Pós-Graduação em Psicologia

Rua Alexandre Rodrigues Barbosa, 45 - 13251-040 - Itatiba-SP

E-mail: gasalves@hotmail.com
} 
trabalho.

No capítulo 11, Indicadores de violência e maus-tratos, as autoras Katia Regiane Tanaka e Rita Aparecida Romaro analisam teoricamente a violência doméstica. As autoras também fizeram uma discussão acerca da formação de profissionais da saúde, que devem se preocupar na avaliação dos atos agressivos e de maus-tratos, já que isso implicaria a identificação dessas ocorrências.
Trata-se de um livro muito bem organizado, com temas pertinentes à temática, também discutindo aspectos teóricos e experiências práticas sobre o fenômeno da violência, que se mostra tão presente na atualidade em diversos contextos. Essa obra traz contribuições importantes para a área da saúde, principalmente, e evidencia a importância da formação dos profissionais da área.

Sobre a autora:

Gisele Aparecida da Silva Alves é acadêmica do curso de Psicologia e vinculada ao Programa de Iniciação Científica (PIC) da Universidade São Francisco, bolsista PIBIC/CNPq. 